\title{
Blood's Concentration of Lead and Arsenic Associated with Anemia in Peruvian Children
}

\author{
Ana Maria Linares $\mathbb{D}^{\mathrm{D}},{ }^{1}$ Jason $M$. Unrine $\mathbb{D}^{\mathrm{D}},{ }^{2}$ Amanda Thaxton Wigging $\mathbb{D}^{\mathrm{D}}{ }^{3}$ \\ Juan C. Tantalean $\left(\mathbb{D},{ }^{4}\right.$ and Vlad C. Radulescu $\mathbb{1}^{5}$ \\ ${ }^{1}$ College of Nursing, 751 Rose St, Room 435-A, CON Building, University of Kentucky, Lexington, KY 40536, USA \\ ${ }^{2}$ Environmental Toxicology, Department of Plant and Soil Sciences, Agriculture Science Center North, \\ 1100 S. Limestone St. Room N-122T, University of Kentucky, Lexington, KY 40546, USA \\ ${ }^{3}$ College of Nursing, 751 Rose St, University of Kentucky, Lexington, KY 40536, USA \\ ${ }^{4}$ University San Luis Gonzaga de Ica, Director Bioslab EIRL, Calle Fermin Tanguis 150, San Miguel, Ica, Peru \\ ${ }^{5}$ Pediatric Hematology-Oncology, Hemophilia Treatment Center, Kentucky Children Hospital, 800 Rose St, Suite C 400, \\ University of Kentucky, Lexington, KY 40536, USA
}

Correspondence should be addressed to Ana Maria Linares; am.linares@uky.edu

Received 30 April 2021; Revised 18 June 2021; Accepted 3 July 2021; Published 15 July 2021

Academic Editor: Chunrong Jia

Copyright (c) 2021 Ana Maria Linares et al. This is an open access article distributed under the Creative Commons Attribution License, which permits unrestricted use, distribution, and reproduction in any medium, provided the original work is properly cited.

\begin{abstract}
This exploratory, descriptive cohort study $(N=60)$ determined lead $(\mathrm{Pb})$ and arsenic $(\mathrm{As})$ blood concentrations in Peruvian children and their association with hematological parameters of iron-deficient anemia (IDA) and anthropometric measurement. The mean age of children was 10.8 months $(\mathrm{SD}=4.7)$ and ranged from 3 to 24 months old. Anemia $(\mathrm{Hb}$ levels below $10.5 \mathrm{~g} / \mathrm{dL})$ was found in $20 \%$ of this cohort. Additionally, microcytosis (MCV $<70 \mathrm{fL})$ was present in $54 \%$, and hypochromia $(\mathrm{MCH}<23 \mathrm{pg})$ in $42 \%$ of the group of children. Chi-square analysis showed that $88 \%$ of the children with anemia also had microcytosis and hypochromia $(p<0.001) . \mathrm{Pb}$ and As were detected in $100 \%$ of the infants' blood samples, and the concentrations were significantly higher in older infants than in younger ones. $\mathrm{Pb}$ and As were not associated with the sex, anthropomorphic parameters, or infant hemogram changes. Infants who received iron supplementation were $87 \%$ less likely to have low $\mathrm{Hb}$ compared with those who did not $(\mathrm{OR}=0.13,95 \% \mathrm{CI}=0.02-0.88, p=0.04)$. Herbal tea intake was significantly associated with microcytosis and hypochromia. Our finding uncovered that hematological parameters for anemia are modified in Peruvian children with high levels of microcytosis and hypochromia. Concentrations of $\mathrm{Pb}$ and $\mathrm{As}$ were above method detection limits in all Peruvian children, but these were not associated with IDA or anthropometric measurements. A large study, including other variables, would benefit from allowing a more complex model predicting anemia in Peruvian children.
\end{abstract}

\section{Introduction}

Prevention of anemia in children younger than three years old is critical because anemia has a strong association with neurobehavioral and neurodevelopment delay that continues until adulthood $[1,2]$. Iron-deficient anemia (IDA) limits psychomotor development in children. Despite the correction of anemia, children with IDA experienced poorer long-term performance in cognitive, social, and emotional functions that continue until adulthood [1-3]. In children under three years old, iron $(\mathrm{Fe})$ is essential for proper brain myelination, neurogenesis, and brain cells differentiation [3]. Iron deficiency typically manifests with anemia (low hemoglobin, $\mathrm{Hb}$ ), hypochromia (low mean corpuscular hemoglobin, $\mathrm{MCH}$ ), microcytosis (low mean corpuscular volume, MCV), and anisocytosis (variation in red blood cell size reflected in a high red cell distribution width, RDW).

Most patients with IDA are treated effectively with oral Fe preparations; however, high concentrations of some potentially toxic trace elements in the body may interfere 
with Fe absorption and/or Fe integration in the hemoglobin. IDA in children has been linked to lead/arsenic ( $\mathrm{Pb} / \mathrm{As}$ ) contamination [4-7]. Children with elevated lead $(\mathrm{Pb})$ exposure may develop IDA since $\mathrm{Pb}$ and $\mathrm{Fe}$ use the same gastrointestinal tract transporter, leading to competitive interference of $\mathrm{Fe}$ absorption as well as interfering with several enzymatic steps in the heme synthesis pathway [4, 8-10]. Moreover, animal and human studies have confirmed that IDA increases intestinal absorption of $\mathrm{Pb}$, which puts children at higher health risk $[1,3]$.

One of every two children under three years of age in Peru has IDA [11]. Based on a UNICEF report (2008), Peru has made critical steps toward increasing norms, policies, and programs that promote and protect children's health and rights [12]. However, because Peru is a country with great cultural, ethnic, linguistic, socioeconomic, and geographic diversity, the national averages tend to hide health disparities affecting many children [12]. Studies have shown that Peruvian children have one of the highest IDA rates globally [13-15], with prevalence in endemic areas reaching as high as $76 \%$ in Puno and $51 \%$ in Cusco [11].

Most Peruvian children are regularly screened for IDA after six months old and treated with oral Fe supplements when blood $\mathrm{Hb}$ below the normal values for age is detected [16]. However, the rate of anemia in Peru has remained steady in the last five years despite the government's efforts to reduce it with Fe supplementation program [11, 17].

Evidence about factors associated with IDA in Peruvian children is scarce. One publication reported that anemia in Peru is linked to sociodemographic characteristics such as living outside Lima and Callao, low socioeconomic households, and adolescent mothers [17]. Additionally, other studies described anemia associated with parasitic infestations [18], vitamin deficiency, and nutritional anemia [19]. To the best of our knowledge, no study has been conducted on the potential association between IDA and toxic traceelement exposure in Peruvian children, even though some evidence has shown a high level of contamination in Peruvian water and soil $[20,21]$. This study aimed to identify $\mathrm{Pb}$ and As concentrations in children's blood and their association with IDA hematological parameters in a Peruvian children sample. Secondary, we evaluated anthropometric indices and potential association with hematologic values and potentially toxic trace elements.

\section{Methods}

This exploratory, descriptive cohort study determined toxic trace-elements blood concentrations in Peruvian children and their association with hematological parameters of IDA. The Ethical Medical Committee of the University of San Luis Gonzaga-Ica, Peru, granted IRB approval \# 001-2018.

2.1. Setting. Participants were recruited from four local primary health care outpatient clinics that provide care in the Ica city, Peru. Data were collected in a single encounter in the clinic following a mother/infant visit to their health provider. Recruitment and data collection were conducted during May and June 2019. Inclusion criteria included: mother with a child between 3 to 24 months old, an infant apparently healthy at recruitment, and no known congenital disease. All families granted informed consent. Participants were compensated with \$50 Peruvian soles (around \$15 US dollars) for their participation. All participants with anemia received adequate treatments.

2.2. Sampling. Given the exploratory nature of this study, no a priori power analysis was conducted. However, a sample size of $N=60$ was established considering the time available for the research and recruiting participants' feasibility. Sixty mothers with their children agreed to participate in the study, and the biospecimen collection was completed in $n=41$ children. Unfortunately, nineteen children missed the blood sample collection at the time scheduled in the clinic. Efforts to reschedule the blood collection were unsuccessful.

2.3. Procedural. Nurses collected survey data from the mothers (one-time point), including sociodemographic characteristics, history and type of infant's feeding, and environmental and housing conditions. After completing the survey, infant anthropometric measurements and the blood sample were collected following standardized protocols. All samples were identified with the numerical code assigned to the participant.

2.3.1. Child Anthropometric Measures. Weight, height, and head circumference were measured using a calibrated scale, a calibrated stadiometer, and a meter infant disposable paper tape measure. All measurements were completed in duplicate. We used the World Health Organization (WHO) [22] child growth standards for children between 0 to 24 months old to calculate age- and sex-specific z-score for height, weight, body mass index (BMI), and head circumference (HC). The use of $\mathrm{z}$-scores allows for the comparison of anthropometric measurements at different ages at the time of recruitment.

The infants' blood was collected via venipuncture in two tubes: (1) Microtainer ${ }^{\circledR}$ MAP microtubes by Becton Dickinson (BD) and (2) Vacutainer EDTA tubes, Hemogard ${ }^{\circledR}$ by BD. Blood samples were transported on ice to a local lab. The local lab reported a complete blood count test (CBC), and the additional Vacutainer sample was stored at $-20^{\circ} \mathrm{C}$, waiting for shipping to the US.

2.3.2. Analysis of Samples in the US. Samples were shipped by a courier company that ensured the appropriate temperature (at least $-20^{\circ} \mathrm{C}$ ) of blood samples at all shipping process stages. All samples were delivered to the University of Kentucky and were consigned and stored in the Clinical Center for Translational Science (CCTS) Lab and kept at $-80^{\circ} \mathrm{C}$. Frozen samples of the infants' blood were transferred to the Environmental Chemistry and Toxicology Lab, University of Kentucky, to analyze $\mathrm{Pb}$ and As concentrations.

The samples were digested in ultrapure nitric acid (Aristar Ultra; VWR) and analyzed to determine $\mathrm{Pb}$ and $\mathrm{As}$ 
concentrations using inductively coupled plasma mass spectrometry (Agilent $7500 \mathrm{cx}$; Santa Clarita, CA, USA) based on previously validated methods [23]. Quality control procedures included analysis of procedural blanks, initial calibration verification, and analysis of standard reference materials (NIST SRM 955c, Toxic Metals in Caprine Blood; National Institute of Standards and Technology, Gaithersburg, MD, USA).

2.4. Data Analysis. Descriptive analysis was accomplished using means and standard deviations, median and interquartile range, or frequency distributions. We dichotomized the hematological parameters based on normal hematologic values in children (mean -2 SD) [24] to determine chronic medical conditions such as (a) anemia, $\mathrm{Hb}<10.5 \mathrm{~g} / \mathrm{dL}$; (b) microcytosis, MCV $<70.0 \mathrm{fL}$; and (c) hypochromia, $\mathrm{MCH}<23.0 \mathrm{pg}$ [24]. Chi-square tests of association were used to evaluate associations among low hematological indices and the sex of the child. To evaluate associations among hematological values (anemia, microcytosis, and hypochromia) with age and anthropometric $\mathrm{z}$-scores, the two-sample $t$-test was used; and the Man$n$-Whitney $U$ test was used for association with levels of toxic trace elements in infant blood. Spearman's product correlation was used to determine whether trace elements correlate with children's age and anthropometric measurements. We used linear regression models to identify predictors of anthropometric z-scores. Finally, three logistic regression models were used to identify predictors of alteration of the hematological parameters listed above. All data analysis was conducted using SAS version 9.4, and we used a $p$-value of $\leq 0.05$ to be statistically significant.

\section{Results}

Demographic characteristics are shown in Table 1. The mean age of children was 10.8 months $(\mathrm{SD}=4.7)$ and ranged from 3 to 24 months. Most mothers had high school or GED education levels (64\%) and have health insurance (70\%), and household income was just enough to cover basic needs (62\%). Most of the houses were solid construction (52\%) with a concrete floor (66\%). Current infant feeding status showed that most infants were fed with breast milk (88\%), and $82 \%$ received complementary foods. More than half of the children (55\%) received iron supplementation and got herbal teas $(72 \%)$.

3.1. Hematological Parameters of Infant Blood. The CBC was reported in $n=41$ samples of infants' blood (two samples were coagulated). Anemia (Hb levels $<10.5 \mathrm{~g} / \mathrm{dL}$ ) was found in $20 \%$ of this cohort. Additionally, microcytosis $(\mathrm{MCV}<70.0 \mathrm{fL})$ was present in $54 \%$ and hypochromia $(\mathrm{MCH}<23.0 \mathrm{pg})$ in $42 \%$ of the group of children (Table 1$)$. There was a significant association between children with anemia and microcytosis $(p=0.009)$ or hypochromia $(88 \%$, $p=0.003$ ). Moreover, we found that about half of the children have microcytosis and hypochromia without anemia. Additionally, microcytosis was significantly more common in females than males ( $79 \%$ vs. $43 \%$ respectively, $p=0.02$, results not shown in tables). Age of the child was significantly $(p=0.01)$ associated with microcytosis; children with microcytosis were older (mean 13.23, $\mathrm{SD}=4.6$ months) than children without microcytosis (mean 9.53, SD 4.6 months).

3.2. Infants' Anthropometric Characteristics. Children's average weight, height, BMI, and $\mathrm{HC}$ z-score calculated according to the WHO standards were $0.26(\mathrm{SD}=1.22)$, $-0.16(\mathrm{SD}=1.33), 0.45(\mathrm{SD}=1.23)$, and $-1.29(\mathrm{SD}=1.90)$, respectively (Table 1 ). There was no significant difference between groups of children with or without alteration of hematological levels (anemia, microcytosis, and hypochromia) and weight, height, and BMI z-scores. The weight $\mathrm{z}$-score correlated positively with height, $\mathrm{HC}$, and BMI $\mathrm{Z}$-scores (Table 2). Finally, child sex, age, and $\mathrm{Pb}$ and $\mathrm{As}$ concentrations were not associated $(p>0.05)$ with anthropometric z-scores in this sample of Peruvian children.

\subsection{Infant Blood Trace-Elements Concentrations.}

Trace-elements analyses were conducted in 42 infants' blood samples. $\mathrm{Pb}$ and $\mathrm{As}$ were detected in $100 \%$ of the infants' blood samples. The median (interquartile range, IQR) concentration of $\mathrm{Pb}$ was $1.60(\mathrm{IQR}=1.72) \mu \mathrm{g} / \mathrm{dL}$, while the median As concentration was $1.36(\mathrm{IQR}=0.71) \mu \mathrm{g} / \mathrm{L}(\mathrm{Ta}-$ ble 1$). \mathrm{Pb}$ and As were positively and significantly $(p<0.05)$ associated with the age of the children (Table 2). However, $\mathrm{Pb}$ and As blood concentrations were not associated with hematological levels and the sex of the child.

3.4. Predictors of Anemia. We ran three logistic regression models to define predictors of anemia, microcytosis, and hypochromia (Table 3). First, the logistic regression modeling factors associated with low hemoglobin showed that the overall model was not significant (Chi-square $=6.7$, $p=0.08$ ), even though iron supplementation was significantly associated with levels of $\mathrm{Hb}$; infants who received iron supplementation were $87 \%$ less likely to have low hemoglobin compared with those who did not $(\mathrm{OR}=0.13,95 \%$ $\mathrm{CI}=0.02-0.88, p=0.04) . \mathrm{Pb}$ and As blood concentrations were not related to low $\mathrm{Hb}$ status. We did not include herbal tea in this model because none of the babies with low $\mathrm{Hb}$ received herbal teas.

The second model showed predictors of microcytosis. The overall logistic model was significant (Chisquare $=10.42, p=0.03$ ). Infants who were given herbal teas were significantly more likely to have microcytosis $(\mathrm{OR}=13.34,95 \% \mathrm{CI}=1.35-131.74, p=0.02)$ compared with those who did not drink herbal teas (Table 3). Finally, the hypochromia overall model was also significant (Chisquare $=10.55, p=0.03)$. Infants who were given herbal teas were significantly more likely to have hypochromia $(\mathrm{OR}=13.04,95 \% \mathrm{CI}=1.25-136.35, \quad p=0.03)$ compared with those who did not drink herbal teas. Similar to the other models, $\mathrm{Pb}$ and As blood concentrations were not significant (Table 3). 
Table 1: Descriptive statistics of study variables $(N=60)$.

\begin{tabular}{|c|c|}
\hline & Mean (SD), $n(\%)$ or median (interquartile range, IQR) \\
\hline Child age (months) & $10.8(4.7)$ \\
\hline \multicolumn{2}{|l|}{ Outpatient clinic } \\
\hline A & $24(40 \%)$ \\
\hline $\mathrm{B}$ & $17(28 \%)$ \\
\hline $\mathrm{C}$ & $6(10 \%)$ \\
\hline $\mathrm{D}$ & $13(22 \%)$ \\
\hline \multicolumn{2}{|l|}{ Mother education level } \\
\hline Elementary school & $8(13 \%)$ \\
\hline High School/GED & $38(64 \%)$ \\
\hline Some college education & $14(23 \%)$ \\
\hline \multicolumn{2}{|l|}{ Health insurance } \\
\hline Yes & $42(70 \%)$ \\
\hline No & $18(30 \%)$ \\
\hline \multicolumn{2}{|l|}{ Household income is enough to cover } \\
\hline Less than basic needs & $18(30 \%)$ \\
\hline Only basic needs & $37(62 \%)$ \\
\hline More than basic needs & $5(8 \%)$ \\
\hline \multicolumn{2}{|l|}{ Construction of house } \\
\hline Clay & $2(3 \%)$ \\
\hline Wood & $17(28 \%)$ \\
\hline Cement-solid & $31(52 \%)$ \\
\hline Other & $10(17 \%)$ \\
\hline \multicolumn{2}{|l|}{ Floor type } \\
\hline Soil-sand & $16(27 \%)$ \\
\hline Cardboard & $1(2 \%)$ \\
\hline Cement-solid & $40(66 \%)$ \\
\hline Tile & $3(5 \%)$ \\
\hline \multicolumn{2}{|l|}{ Sex of the child } \\
\hline Female & $25(42 \%)$ \\
\hline Male & $20(33 \%)$ \\
\hline Unknown & $15(25 \%)$ \\
\hline \multicolumn{2}{|l|}{ Feeding with breast milk } \\
\hline Yes & $53(88 \%)$ \\
\hline No & $7(12 \%)$ \\
\hline \multicolumn{2}{|l|}{ Complementary foods } \\
\hline Yes & $49(82 \%)$ \\
\hline No & $11(18 \%)$ \\
\hline \multicolumn{2}{|l|}{ Infant iron supplementation } \\
\hline Yes & $33(55 \%)$ \\
\hline No & $27(45 \%)$ \\
\hline \multicolumn{2}{|l|}{ Infant drink herbal teas } \\
\hline Yes & $43(72 \%)$ \\
\hline No & $17(28 \%)$ \\
\hline \multicolumn{2}{|l|}{ Infant anemia by age $\mathrm{Hb}<10.5 \mathrm{~g} / \mathrm{dL}^{\mathrm{a}}$} \\
\hline Yes & $8(20 \%)$ \\
\hline No & $33(80 \%)$ \\
\hline \multicolumn{2}{|l|}{ Infant microcytosis $\mathrm{MCV}<70.0 \mathrm{fL}^{\mathrm{a}}$} \\
\hline Yes & $22(54 \%)$ \\
\hline No & $19(46 \%)$ \\
\hline \multicolumn{2}{|l|}{ Infant hypochromia $\mathrm{MCH}<23.0 \mathrm{pg}^{\mathrm{a}}$} \\
\hline Yes & $17(42 \%)$ \\
\hline No & $24(58 \%)$ \\
\hline Infant weight $\mathrm{z}$-score ${ }^{\mathrm{b}}$ & $0.26(1.22)$ \\
\hline Infant height $\mathrm{z}$-score ${ }^{\mathrm{b}}$ & $-0.16(1.33)$ \\
\hline Infant BMI z-score ${ }^{\mathrm{b}}$ & $0.45(1.23)$ \\
\hline Infant head circumference $\mathrm{z}$-score ${ }^{c}$ & $-1.29(1.90)$ \\
\hline Infant blood lead concentration $(\mu \mathrm{g} / \mathrm{dL})^{\mathrm{d}}$ & 1.60 (IQR 1.72) \\
\hline Infant blood arsenic concentration $(\mu \mathrm{g} / \mathrm{L})^{\mathrm{d}}$ & 1.36 (IQR 0.71$)$ \\
\hline
\end{tabular}

${ }^{\mathrm{a}} n=41 ;{ }^{\mathrm{b}} n=44 ;{ }^{\mathrm{c}} n=43 ;{ }^{\mathrm{d}} n=42$. 
TABLE 2: Correlation of infants' age, blood toxic elements, and anthropometric measurements $(n=42)$.

\begin{tabular}{|c|c|c|c|c|c|c|}
\hline Variable & 1 & 2 & 3 & 4 & 5 & 6 \\
\hline 1. Age & - & & & & & \\
\hline 2. As & $0.37^{*}$ & - & & & & \\
\hline 3. $\mathrm{Pb}$ & $0.35^{*}$ & 0.26 & - & & & \\
\hline 4. Weight $\mathrm{z}$-score & -0.9 & -0.04 & -0.06 & - & & \\
\hline 5. Height $\mathrm{z}$-score & -0.23 & -0.04 & -0.00 & $0.45^{* *}$ & - & \\
\hline 6. HC z-score & -0.17 & -0.25 & -0.03 & $0.32^{*}$ & 0.24 & - \\
\hline 7. BMI z-score & -0.12 & -0.03 & -0.10 & $0.82^{* *}$ & 0.11 & $0.33^{*}$ \\
\hline
\end{tabular}

${ }^{*} p<0.05 ;{ }^{* *} p<0.01$.

TABLE 3: Logistic regression examining predictors of hematological (low hemoglobin, microcytosis, and hypochromia) parameters associated with $\mathrm{Pb}$ and $\mathrm{As}(n=40)^{*}$.

\begin{tabular}{|c|c|c|c|c|c|c|c|c|c|}
\hline & \multicolumn{3}{|c|}{ Low hemoglobin } & \multicolumn{3}{|c|}{ Microcytosis } & \multicolumn{3}{|c|}{ Hypochromia } \\
\hline & OR & $95 \%$ CI for OR & $p$ & OR & $95 \% \mathrm{CI}$ for $\mathrm{OR}$ & $p$ & OR & $95 \%$ CI for OR & $p$ \\
\hline Iron supplementation & & & & & & & & & \\
\hline $\begin{array}{l}\text { Yes } \\
\text { No }\end{array}$ & $\begin{array}{l}0.13 \\
\text { Ref }\end{array}$ & $0.02-0.88$ & 0.04 & $\begin{array}{l}1.39 \\
\text { Ref }\end{array}$ & $0.16-3.26$ & 0.67 & $\begin{array}{c}0.83 \\
\text { Ref }\end{array}$ & $0.18-3.78$ & 0.81 \\
\hline Herbal teas ${ }^{\mathrm{a}}$ & & & & & & & & & \\
\hline $\begin{array}{l}\text { Yes } \\
\text { No }\end{array}$ & - & - & - & $\begin{array}{c}13.34 \\
\text { Ref }\end{array}$ & $1.35-131.74$ & 0.03 & $\begin{array}{c}13.04 \\
\text { Ref }\end{array}$ & $1.25-136.35$ & 0.03 \\
\hline Blood lead concentration $(\mu \mathrm{g} / \mathrm{dL})$ & 1.27 & $0.62-2.12$ & 0.44 & 1.35 & $0.70-2.61$ & 0.36 & 1.27 & $0.68-2.37$ & 0.45 \\
\hline Blood arsenic concentration $(\mu \mathrm{g} / \mathrm{L})$ & 0.30 & $0.03-2.78$ & 0.29 & 0.41 & $0.07-2.17$ & 0.29 & 0.20 & $0.03-1.23$ & 0.08 \\
\hline
\end{tabular}

* 2 blood samples were coagulated. ${ }^{a}$ Low hemoglobin not adjusted for herbal teas due to complete separation.

\section{Discussion}

This study's primary aim was to analyze the association of $\mathrm{Pb}$ and As concentrations in infants' blood and their association with hematological parameters in Peruvian children. The levels of anemia detected in our sample based on $\mathrm{Hb}$ were lower (20\%) compared with the Peruvian government levels (41\%) in the area that we collected the samples [16]. The difference could be related to the testing methods used; while Peruvian clinics used a capillary sample to collect and analyze blood (HemoCue ${ }^{\circledR} \mathrm{Hb} 201+$ ) [25], we used a venipuncture blood sample, and the hemogram or $\mathrm{CBC}$ was analyzed by a Peruvian lab that followed international standards.

Results from HemoCue ${ }^{\circledR}$ Hb 201+ are highly correlated to those yielded by traditional CBC $[26,27]$, but differences in capillary sampling may produce systematic errors that influence results [28]. We also found that a significant percentage $(88 \%)$ of children with anemia also had microcytosis and hypochromia. It is essential to notice that Peruvian infants are only tested via a capillary method without a hemogram's follow-up when the $\mathrm{Hb}$ result is low. Lack of analysis of hemogram or CBC might hide if microcytosis or hypochromia are presently preventing a clear picture of the hematological alteration that Peruvian children have.

It is known that microcytosis and hypochromia are the hallmarks of IDA, but other conditions might produce microcytosis and hypochromia that may be confused with IDA $[1,29]$. Our results showed that some Peruvian children in our sample had microcytosis and hypochromia without IDA; this has been associated with other conditions, including genetic alterations like the thalassemia trait and anemia of chronic disease (ACD) [1]. A study to evaluate other potential variables related to anemia, including genetic traits, is needed in Peruvian children to clarify why they are more likely to develop anemia in the early stage of life. We highly recommend that children positive for anemia based on the HemoCue ${ }^{\circledR} \mathrm{Hb} 201+$ should be followed up with a hemogram to allow identification of other hematological alterations that might define other causes of IDA.

Anthropometric mean $\mathrm{z}$-scores were normal according to the WHO standards when we considered children from the four clinics. We found no association between $\mathrm{z}$-scores and age, sex, hematological levels, and $\mathrm{Pb}$ or As concentrations. Similar results have been reported in a cohort of Canadian children. In addition, the researchers found no significant association between children's blood concentration of $\mathrm{Pb}$ and $\mathrm{As}$ with childhood $\mathrm{BMI}$, weight, or height in boys or girls [30].

Our findings showed that $100 \%$ of this cohort of children had fairly low concentrations of $\mathrm{Pb}$ and $\mathrm{As}$ in their blood. Our data showed a significant association between age and concentrations of $\mathrm{Pb}$ and $\mathrm{As}$; as the child gets older, concentrations of $\mathrm{Pb}$ and $\mathrm{As}$ in blood increase. Although traceelements concentrations were low, it concerns that we found these elements in $100 \%$ of the blood samples. Thresholds of blood $\mathrm{Pb}$ levels that have been associated with neurodevelopmental effects have tended to decrease over the years as research accumulates. The $\mathrm{CDC}$ has reported that $\mathrm{a} \mathrm{Pb}$ concentration of $>5 \mu \mathrm{g} / \mathrm{dL}$ is used to indicate possible adverse neurodevelopmental outcomes for children older than one year [31]. Additionally, other institutions reported that a $\mathrm{Pb}$ concentration in children of $1.40 \mu \mathrm{g} / \mathrm{dL}$ and higher 
should be investigated [32]. In a cohort of Canadian children, the median $\mathrm{Pb}$ level in blood reported was $0.66 \mu \mathrm{g} / \mathrm{dL}$ [30]. In our cohort of Peruvian children's blood samples, we found that the median concentration was $1.60 \mu \mathrm{g} / \mathrm{dL}$, which is more than double compared with Canadian children but under the threshold suggested by the CDC. Nevertheless, our data showed that the concentration of $\mathrm{Pb}$ was not significantly associated with hematological or anthropometric alterations.

Arsenic causes a neurodevelopmental effect and has been associated with deficits in intelligence and memory [6]. As concentration in Peruvian infants' blood was extremely low $(1.36 \mu \mathrm{g} / \mathrm{L})$ compared with the acceptable threshold concentration of $<13 \mu \mathrm{g} / \mathrm{L}$ [33]. Still, Peruvian children's As concentrations were much higher than those reported for Canadian children (1.36 vs. $0.46 \mu \mathrm{g} / \mathrm{L}$, respectively) [30]. Differences in diet may explain why $100 \%$ of Peruvian children have As in their blood. It is known that the Peruvian diet is high in the consumption of rice and seafood, which contain As [34, 35]. However, As contained in seafood is principally in the organic form, which is less toxic [35]. As concentration was not associated with hematological or anthropometric alterations in this sample of Peruvian children, which is similar to results in Canadian children [30].

The final logistic regression model showed that children supplemented with Fe were significantly less likely to be anemic. This is a promising result considering that the Peruvian government is establishing an iron supplementation program for children after six months old [16]. Therefore, a revision of inequality among Peruvian children on getting iron supplementation is warranted.

Microcytosis was detected in 54\% of Peruvian children, and it was associated with the use of herbal tea. Moreover, hypochromia was detected in $42 \%$ of children, and the model showed that it was also predicted by increased intake of herbal teas. Tea interferes with $\mathrm{Fe}$ absorption and can lead to IDA when consumed in large quantities $[36,37]$. This finding uncovers the need to educate the mothers about the permissive effect of herbal tea intake on $\mathrm{Fe}$ absorption in young children.

4.1. Strengths and Limitations. The principal strength of this study is that it provides evidence that $\mathrm{Pb}$ and $\mathrm{As}$ are present in blood samples of Peruvian children, even when their concentrations were low compared with the threshold proposed by the CDC $[33,38]$ and were not associated with IDA. On the other hand, the study has limitations as the sample size; mainly, it limited the inclusion of other variables in the logistic regression models. Additionally, recruitment was limited to one location in the country, which restricted the generalization of the findings. The sample collection methodology limited our ability to perform direct measurements of iron, ferritin, transferrin saturation, or genetic testing for thalassemia. However, with the limited resources and time allocated to this study, we generated this first approach to detect potential trace-element exposure associated with IDA in Peruvian children. A large study, including other variables, would benefit from allowing a more complex model predicting anemia in Peruvian children.

\section{Conclusion}

Our finding uncovered that hematological parameters for anemia are modified in Peruvian children with high levels of microcytosis and hypochromia. This study showed that concentrations of $\mathrm{Pb}$ and As were detectable in all Peruvian children and were positively and significantly associated with the child's age; however, these toxic trace elements were not associated with IDA or anthropometric measurements. In addition, our findings showed that receiving Fe supplementation significantly decreased the risk of having anemia. Consumption of herbal tea was significantly associated with microcytosis and hypochromia in Peruvian children.

\section{Data Availability}

The data are available by request to the first author.

\section{Disclosure}

The content is solely the responsibility of the authors and does not necessarily represent the official views of NIH and NIEHS.

\section{Conflicts of Interest}

The authors declare no potential conflicts of interest with respect to the research, authorship, and/or publication of this article.

\section{Acknowledgments}

The authors acknowledge the assistance of N. Pastor, a faculty member with a group of senior nursing students from the School of Nursing, and Dr. Castaneda, Office of Research Integrity, University of San Luis Gonzaga-Ica, Peru. The authors also acknowledge the assistance of S. Shrestha from the University of Kentucky Department of Plant and Soil Sciences. This project or publication has different sources of funding: (1) Fulbright Foundation through a research award to the first author of this publication; (2) Research Pilot Fund, College of Nursing, University of Kentucky; (3) NIH National Center for Advancing Translational Sciences through grant no. UL1TR001998; (4) UK-CARES through Grant P30 ES026529.

\section{References}

[1] G. Subramaniam and M. Girish, "Iron deficiency anemia in children," The Indian Journal of Pediatrics, vol. 82, no. 6, pp. 558-564, 2015.

[2] N. Zavaleta and L. Astete-Robilliard, "Effect of anemia on child development: long-term consequences," Revista Peruana de Medicina Experimental y Salud Pública, vol. 34, no. 4, pp. 716-722, 2017. 
[3] M. Wang, "Iron deficiency and other types of anemia in infants and children," American Family Physician, vol. 93, no. 4, pp. 270-278, 2016.

[4] M. Hauptman, R. Bruccoleri, and A. D. Woolf, "An update on childhood lead poisoning," Clinical Pediatric Emergency Medicine, vol. 18, no. 3, pp. 181-192, 2017.

[5] G. López-Rodríguez, M. Galván, M. González-Unzaga, J. Hernández Ávila, and M. Pérez-Labra, "Blood toxic metals and hemoglobin levels in Mexican children," Environmental Monitoring and Assessment, vol. 189, no. 4, p. 179, 2017.

[6] M. Tolins, M. Ruchirawat, and P. Landrigan, "The developmental neurotoxicity of arsenic: cognitive and behavioral consequences of early life exposure," Annals of Global Health, vol. 80, no. 4, pp. 303-314, 2014.

[7] C. Weinhouse, E. J. Ortiz, A. J. Berky et al., "Hair mercury level is associated with anemia and micronutrient status in children living near artisanal and small-scale gold mining in the Peruvian amazon," The American Journal of Tropical Medicine and Hygiene, vol. 97, no. 6, pp. 1886-1897, 2017.

[8] C.-J. Chen, T.-Y. Lin, C.-L. Wang, C.-K. Ho, H.-Y. Chuang, and $\mathrm{H} . \mathrm{S}$. $\mathrm{Yu}$, "Interactive effects between chronic lead exposure and the homeostatic iron regulator transport HFE polymorphism on the human red blood cell mean corpuscular volume (MCV)," International Journal of Environmental Research and Public Health, vol. 16, no. 3, p. 354, 2019.

[9] (ATSDR) AfTSaDR, Toxicologia Profile of Lead Atlanta, ATSDR, Atlanta, Georgia, 2011, https://www.atsdr.cdc.gov/ toxprofiles/tp13-c2.pdf.

[10] Center for Disease Control and Prevention, Toxicological Profile For Lead, ATSDR, Atlanta, Georgia, 2020.

[11] Instituto Nacional de Salud (INS), Anemia en Ninos Menores de 3 anos: Modelo Causal Intervencions para Combatirla, Centro Nacional de Alimentacion y Nutricion, INS, Cuernavaca, Mexico, 2016.

[12] UNICEF and INEI, Situation of Children in Peru: Executive Summary, United Nations Children's Fund (UNICEF), Lima, Peru, 2008.

[13] J. P. Aparco and L. Huamán-Espino, "Recommendations for Interventions with Iron Supplements: Lessons Learned in a Community Trial in Four Regions of Peru," Revista Peruana de Medicina Experimental y Salud Pública, vol. 34, no. 4, pp. 709-715, 2017.

[14] J. L. Finkelstein, K. O. O’Brien, S. A. Abrams, and N. Zavaleta, "Infant iron status affects iron absorption in Peruvian breastfed infants at 2 and 5 mo of age," The American Journal of Clinical Nutrition, vol. 98, no. 6, pp. 1475-1484, 2013.

[15] M. F. Mujica-Coopman, A. Brito, D. López de Romaña, I. Ríos-Castillo, H. Cori, and M. Olivares, "Prevalence of anemia in Latin America and the caribbean," Food and Nutrition Bulletin, vol. 36, pp. S119-S128, 2015.

[16] Peru MdSd, Plan Nacional para la Reduccion y Control de la Anemia Materno Infantil y la Desnutricion Cronica Infantil en el Peru: 2017-2021, MINSA, Lima, Peru, 2017.

[17] J. E. Velásquez-Hurtado, Y. Rodríguez, M. Gonzáles et al., "Factors associated with anemia in children under three years of age in Peru: analysis of the Encuesta Demografica y de Salud Familiar, ENDES," Biomédica, vol. 36, no. 2, pp. 220-229, 2016.

[18] E. Gonzales, L. Huamán-Espino, C. Gutiérrez, J. P. Aparco, and J. Pillaca, "Characterization of anemia in children under five years of age from urban areas of Huancavelica and Ucayali, Peru," Revista Peruana de Medicina Experimental y Salud Pública, vol. 32, no. 3, pp. 431-439, 2015.
[19] J. Pajuelo, M. Miranda, and R. Zamora, "Prevalence of vitamin a deficiency and anemia in children under five years of age in Peru," Revista Peruana de Medicina Experimental y Salud Pública, vol. 32, no. 2, pp. 245-251, 2015.

[20] C. M. George, L. Sima, M. H. J. Arias et al., "Arsenic exposure in drinking water: an unrecognized health threat in Peru," Bulletin of the World Health Organization, vol. 92, no. 8, pp. 565-572, 2014.

[21] A. van Geen, C. Bravo, V. Gil, S. Sherpa, and D. Jack, "Lead exposure from soil in Peruvian mining towns: a national assessment supported by two contrasting examples," Bulletin of the World Health Organization, vol. 90, no. 12, pp. 878-886, 2012.

[22] World Health Organization, WHO Child Growth Standards, US: WHO, New York City, NY, USA, 2006.

[23] C. D. Palmer, M. E. Lewis, C. M. Geraghty, F. Barbosa, and P. J. Parsons, "Determination of lead, cadmium and mercury in blood for assessment of environmental exposure: a comparison between inductively coupled plasma-mass spectrometry and atomic absorption spectrometry," Spectrochimica Acta Part B: Atomic Spectroscopy, vol. 61, no. 8, pp. 980-990, 2006.

[24] S. H. N. D. Orkin, D. Ginsburg, A. T. Look, D. E. Fisher, and I. V. S. E. Lux, Mathan and Oski's Hematology of Infancy and Childhood, Saunders-Elsevier, Canada, 2009.

[25] HemoCue, “The HemoCue ${ }^{\circledR}$ Hb 201+System 2019," https:// www.hemocue.us/hb-201/https://www.hemocue.us/wp-content /uploads/2020/08/MMUS-01164-Hb-201-Product-Profile.pdf.

[26] H. B. Anastasio, R. Mardis, A. Khalifeh, J. Baxter, V. Berghella, and H. B. Al-Kouatly, "Time advantage of HemoCue versus traditional complete blood count during cordocentesis," The Journal of Maternal-Fetal \& Neonatal Medicine, vol. 34, no. 12, pp. 1914-1918, 2019.

[27] A. Jain, N. Chowdhury, and S. Jain, "Intra- and inter-model reliability of hemocue $\mathrm{Hb} 201+$ and HemoCue $\mathrm{Hb} 301$ devices," Asian Journal of Transfusion Science, vol. 12, no. 2, pp. 123-126, 2018.

[28] A. Jain and N. Chowdhury, "Comparison of the accuracy of capillary hemoglobin estimation and venous hemoglobin estimation by two models of HemoCue against automated cell counter hemoglobin measurement," Asian Journal of Transfusion Science, vol. 14, no. 1, pp. 49-53, 2020.

[29] M. M. Heeney and K. E. Finberg, "Iron-refractory iron deficiency anemia (IRIDA)," Hematology/Oncology Clinics of North America, vol. 28, no. 4, pp. 637-652, 2014.

[30] J. Ashley-Martin, L. Dodds, T. E. Arbuckle et al., "Blood metal levels and early childhood anthropometric measures in a cohort of Canadian children," Environmental Research, vol. 179, Article ID 108736, 2019.

[31] Prevention CfDC, CDC Response to Advisory Committee on Childhood Lead Poisoning Prevention Recommendations, CfDC, Atlanta, GA, USA, 2012.

[32] Department of Health NYS, What your child's blood lead test means, New York State: Department of Health, New York City, NY, USA.

[33] Laboratories MC, "Rochester Interpretative Handbook," https:// www.mayocliniclabs.com/test-catalog/pod/MayoTestCatalog-Roc hester--SortedByTestName-duplex-interpretive.pdf.

[34] Food and Agriculture Organization of the United Nations, Rice Is Life: International Rice Commission Meets in Peru, FAO, Washington, DC, USA, 2006.

[35] M. Medina-Pizzali, P. Robles, M. Mendoza, and C. Torres, "Arsenic Intake: Impact in Human Nutrition and Health," 
Revista Peruana de Medicina Experimental y Salud Pública, vol. 35, no. 1, pp. 93-102, 2018.

[36] E. Temme and P. Van Hoydonck, "Tea consumption and iron status," European Journal of Clinical Nutrition, vol. 56, no. 5, pp. 379-386, 2002.

[37] F. S. Fan, "Iron deficiency anemia due to excessive green tea drinking," Clinical Case Reports, vol. 4, no. 11, pp. 1053-1056, 2016.

[38] Center for Disease Control and Prevention, Childhood Lead Poisoning Prevention Program: CDC, 2021, https://www.cdc. gov/nceh/lead/default.htm. 